\title{
A Large-Capacity Capacitor Simulator with an Inner-Series Resistor
}

\author{
Masayuki Okamoto* Member, \\ Eiji Hiraki** \\ Toshihiko Tanaka** Senior Member, \\ Atsushi Tanaka** \\ Member \\ Non-member
}

(Manuscript received Dec. 27, 2012, revised March 26, 2013)

\begin{abstract}
This paper proposes a universal large-capacity capacitor simulator. The proposed simulator consists of a main chemical capacitor and three-leg IGBTs. One leg of the IGBTs acts as a bidirectional dc-dc converter. The other two legs are used for a single-phase PWM rectifier. In the capacitor-charging operation, the bidirectional dc-dc converter is used as a boost converter. Most of the power supplied by the load is supplied to the utility through the single-phase PWM rectifier. In the capacitor-discharging operation, the bidirectional dc-de converter acts as a buck converter. Most of the power supplied to the load is from the utility through the single-phase PWM rectifier. A new control method, which can perform as an inner-series resistor in a supercapacitor (SC), is also proposed for an SC simulator. The basic principle of the proposed capacitor simulator is discussed in detail. The validity and high applicability of the proposed large-capacity capacitor simulator are confirmed using PSIM software. A prototype experimental model is constructed and tested. The experimental results demonstrate that the proposed capacitor simulator acts both as an ideal large-capacity capacitor and as an SC with an inner-series resistor.
\end{abstract}

Keywords: ideal capacitor simulator, supercapacitor simulator, bidirectional dc-dc converter, PWM rectifier, inner-series resistor, single-phase PLL circuit

\section{Introduction}

Fuel cells (FCs) systems have been actively researched as a candidate of an electrical energy source for residential use and EVs ${ }^{(1)(2)}$. In the FCs system for these use, large-capacity energy storage devices are used to improve a response lag of reformer ${ }^{(3)}$. For the large-capacity energy storage devices, lead-acid batteries are still mainly used because of their low cost. Lead-acid batteries, however, produce toxic industrial waste. A super capacitor (SC) consists of more environmentfriendly materials, which can solve the problem of toxic industrial waste.

SCs are often used in industrial applications. However, large-scale energy storage devices used in voltage sag compensators and so forth with SCs cannot be constructed at the laboratory scale because of their high cost. An SC simulator with two electrolytic capacitors and dc-dc converters has been proposed ${ }^{(4)}$, which the authors named an EDLC simulator. In the proposed SC simulator, the power in the capacitordischarging operation is supplied to the load from an auxiliary dc power supply through a dc-dc converter. In the capacitor-charging operation by the load, the surplus power, which cannot be stored in the electrolytic capacitor, is consumed by external resistors. However, the power consumption by the resistor causes a problem that a laboratory requires

\footnotetext{
Ube National College of Technology

2-14-1, Tokiwadai, Ube 755-8555, Japan

** Graduate School of Yamaguchi University

2-16-1, Tokiwadai, Ube 755-8611, Japan

${ }^{* * *}$ The Chugoku Electric Power Co., Inc.

4-33, Komachi, Naka-ku, Hiroshima 730-8701, Japan
}

the increased contract demand for simulating a large capacity capacitor. Moreover, it is well known that there is an innerseries resistor in an SC. However, the proposed SC simulator cannot act as an inner-series resistor. Thus the proposed SC simulator cannot act as an actual SC. SC simulators with no power consumption that can act as an inner-series resistor are required. Ideal and variable large-capacity capacitors with no inner-series resistors are often needed to construct energy storage systems, which are used as prototype voltage sag compensators and so forth in laboratories. Thus, a variable large-capacity capacitor simulator with/without an inner-series resistor is required in laboratories.

This paper proposes a universal large-capacity capacitor simulator, which can act as an inner-series resistor in an SC. The proposed simulator consists of a main electrolytic capacitor and three-leg IGBTs. One leg is connected to the main electrolytic capacitor and acts as a bidirectional dc-dc converter. The other legs are used for a single-phase PWM rectifier. In the capacitor-charging operation, the bidirectional dc-dc converter is used as a boost converter. Most of the power supplied by the load, which is stored in the proposed capacitor simulator, is injected to the utility through the single-phase PWM rectifier in the operation. In the capacitordischarging operation, the bidirectional dc-dc converter acts as a buck converter. Most of the power supplied to the load from the proposed capacitor simulator is from the utility through the single-phase PWM rectifier in the operation. Thus, the proposed simulator acts as a large-capacity capacitor in both the charging and discharging operations. For an $\mathrm{SC}$ simulator, an inner-series resistor should be included. A new control method, which can act as an inner-series resistor, 


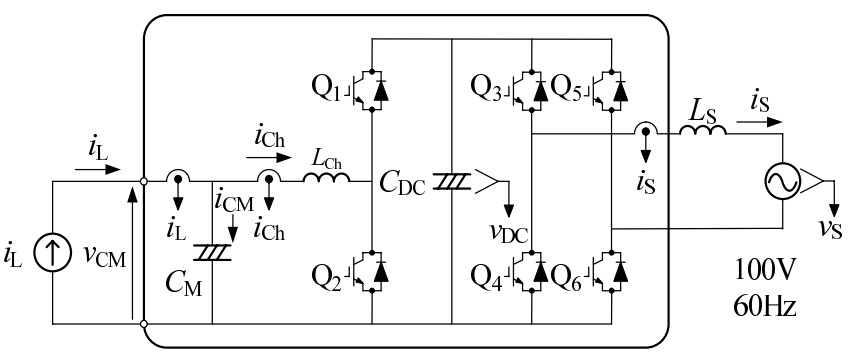

(a) Power circuit diagram of the proposed simulator.

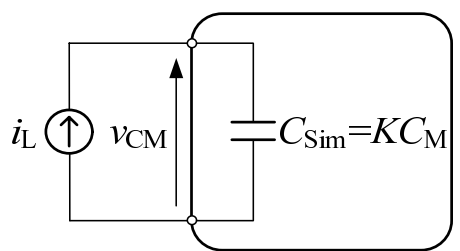

(b) Equivalent circuit for (a)

Fig. 1. Proposed large-capacity capacitor simulator

is also proposed. The basic principle of the proposed capacitor simulator is discussed in detail and then confirmed by digital computer simulation using PSIM software. A prototype experimental model is constructed and tested to verify the validity and high applicability of the proposed large-capacity capacitor simulator. Experimental results demonstrate that the proposed capacitor simulator performs both as an ideal large-capacity capacitor and as an SC with an inner-series resistor.

\section{Proposed Large-Capacity Capacitor Simula- tor}

2.1 System Configuration Fig. 1 shows a block diagram of the proposed large-capacity capacitor simulator. (a) shows a power circuit diagram of the proposed simulator and (b) shows an equivalent circuit for (a). In (a), the area enclosed by the bold line corresponds to the large-capacity capacitor. The proposed simulator consists of a main electrolytic capacitor $C_{\mathrm{M}}$ and three-leg IGBTs. The main electrolytic capacitor $C_{\mathrm{M}}$ acts as a large-capacity capacitor $K C_{\mathrm{M}}$. as shown in (b). One leg of the IGBTs is connected to the main capacitor $C_{\mathrm{M}}$ and is used for a bidirectional dc-dc converter. The other two legs are used for a single-phase PWM rectifier. During the capacitor-charging operation, the bidirectional dc-dc converter consisting of $\mathrm{Q}_{1}$ and $\mathrm{Q}_{2}$ acts as a boost converter, where $\mathrm{Q}_{1}$ acts as a diode and $\mathrm{Q}_{2}$ is used as a switch for the boost converter. Most of the power from the load $i_{\mathrm{L}}$ is injected to the utility by the PWM rectifier through a boost chopper. The output voltage $v_{\mathrm{CM}}$ of the proposed capacitor simulator gradually increases. In the capacitordischarging operation, $\mathrm{Q}_{1}$ and $\mathrm{Q}_{2}$ act as a buck converter, where $\mathrm{Q}_{2}$ acts as a diode and $\mathrm{Q}_{1}$ is used as a switch for the buck converter. Most of the power to the load is from the utility through the PWM rectifier. The output voltage $v_{\mathrm{CM}}$ gradually decreases. Thus, the main capacitor $C_{\mathrm{M}}$ acts as a large-capacity capacitor. No power is consumed in the proposed simulator. The proposed large-capacity capacitor can overcome the problems in (4) described above, which limit the response and consume the surplus power.

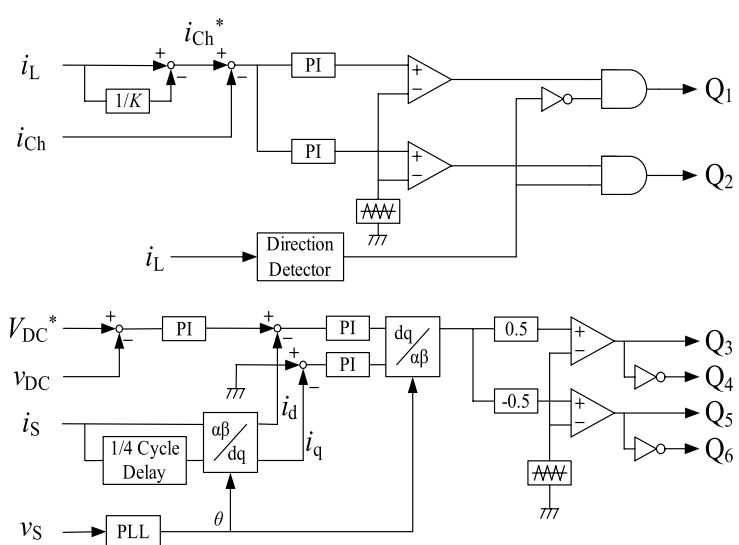

Fig. 2. Control circuit diagram for the proposed largecapacity capacitor simulator in Fig. 1(a)

2.2 Control Method of the Proposed Large-capacity Capacitor Simulator Here the control method of the proposed simulator is discussed. Let the initial value of the capacitor voltage be $V_{\mathrm{INT}}$. The capacitor voltage $v_{\mathrm{C}}$ at time $t$ with the current $i_{\mathrm{C}}$ is generally expressed as

$$
v_{\mathrm{C}}=\frac{1}{C} \int_{0}^{t} i_{\mathrm{C}} d \tau+V_{\mathrm{INT}} .
$$

As shown in Fig. 2, the capacitor current $i_{\mathrm{CM}}$ in Fig. 1(a) is controlled to $i_{\mathrm{CM}}=i_{\mathrm{L}} / K$ by switches $\mathrm{Q}_{1}$ and $\mathrm{Q}_{2}$, which act as either a buck converter or a boost converter. Then, the capacitor voltage $v_{\mathrm{CM}}$ in Fig. 1(a) is given by

$$
\begin{aligned}
v_{\mathrm{CM}} & =\frac{1}{C_{\mathrm{M}}} \int_{0}^{t} \frac{i_{\mathrm{L}}}{K} d \tau+V_{\mathrm{INT}} \\
& =\frac{1}{K C_{\mathrm{M}}} \int_{0}^{t} i_{\mathrm{L}} d \tau+V_{\mathrm{INT}} .
\end{aligned}
$$

Equation (2) implies that the capacity of the dc capacitor $C_{\mathrm{M}}$ in Fig. 1(a) is equivalent to that of the capacitor $K C_{\mathrm{M}}$. Thus, the proposed simulator in Fig. 1 can act as a large-capacity capacitor with no power consumption.

Fig. 2 shows the control circuit diagram for the proposed large-capacity capacitor simulator in Fig. 1. It is well known that a steady-state error remains in a single-phase PWM rectifier when the sine-triangle intercept technique based current feedback control with a PI controller is used. To avoid this steady-state error, an interesting current feedback control scheme on d-q coordinates in single-phase circuits has been proposed ${ }^{(5)}$. However, details of the scheme have not been described. Thus, d-q-transformation-based current feedback control in single-phase circuits has been constructed and tested here. The source voltage $v_{\mathrm{S}}$ is detected, and then the phase information is generated by a single-phase PLL circuit with a transport delay ${ }^{(6)(7)}$. The generated angle $\theta$ is used for the d-q transformation. The source current $i_{\mathrm{S}}$ is detected and is equal to the $\alpha$-phase current $i_{\mathrm{S} \alpha}$. The $\beta$-phase current $i_{\mathrm{S} \beta}$ is obtained through a $T_{\mathrm{S}} / 4$ transport delay block, where $T_{\mathrm{S}}$ is the cycle of the source voltage $v_{\mathrm{S}} . i_{\mathrm{S} \alpha}$ and $i_{\mathrm{S} \beta}$ are transformed to d-q coordinates using a value of $\theta$ generated by the single-phase PLL circuit. Source current feedback with PI controllers is performed using the $\mathrm{d}-\mathrm{q}$ coordinates. Thus, we completely suppress the steady-state error on the source current $i_{\mathrm{S}}$. In the transient state, however, an error between the 


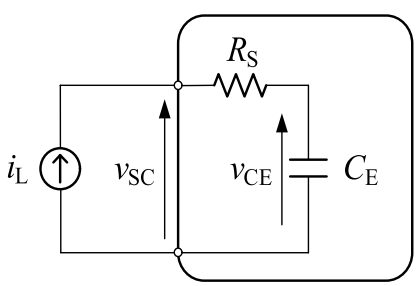

Fig. 3. Equivalent circuit for SC

reference value $i_{\mathrm{S}}^{*}$ and the actual current $i_{\mathrm{S}}$ exists because the $T_{\mathrm{S}} / 4$ transport delay block is included.

2.3 Inner-series Resistor in SC An inner-series resistor can be also included in the proposed large-capacity capacitor simulator to act as an SC. Fig. 3 shows an equivalent circuit for the SC. During the capacitor-charging operation, the output voltage $v_{\mathrm{SC}}$ is given by

$$
v_{\mathrm{SC}}=i_{\mathrm{L}} R_{\mathrm{S}}+v_{\mathrm{CE}},
$$

while during the capacitor-discharging operation, $v_{\mathrm{SC}}$ is given by

$$
v_{\mathrm{SC}}=v_{\mathrm{CE}}-i_{\mathrm{L}} R_{\mathrm{S}} \cdot \ldots \ldots \ldots \ldots \ldots \ldots \ldots \ldots \ldots \ldots \ldots
$$

Equations (3) and (4) show that $v_{\mathrm{SC}}$ jumps by $2 i_{\mathrm{L}} R_{\mathrm{S}}$ when the operation mode of the proposed simulator is changed from the charging operation to the discharging operation or from the discharging operation to the charging operation. This jump in the voltage should be considered in the control circuit in Fig. 2 when performing the SC simulation. Here, a new control method for achieving this voltage jump is proposed. In the proposed method, the control gain $K$ is equal to 1.0 for a short time while the operation mode is changed from capacitor charging to capacitor discharging or from discharging to charging. When the operation mode is changed from discharging to charging, the operation of the switches $\mathrm{Q}_{1}$ and $\mathrm{Q}_{2}$ is changed from the buck operation to the boost operation, and then the control gain $K$ in Fig. 2 is reduced to 1.0 for a short time. If $K=1.0$ in Fig. 2 during the buck operation, then $i_{\mathrm{CM}}$ is equal to $i_{\mathrm{L}}$. This means that the electrolytic capacitor $C_{\mathrm{M}}$ is charged rapidly. Thus, $v_{\mathrm{CM}}$ jumps by $2 i_{\mathrm{L}} R_{\mathrm{S}}$ in a short time. When the operation mode is changed from charging to discharging, the operation of $\mathrm{Q}_{1}$ and $\mathrm{Q}_{2}$ is changed from the boost operation to the buck operation, and then the control gain $K$ in Fig. 2 is also 1.0 for a short time. If $K=1.0$ in Fig. 2 during the boost operation, then $i_{\mathrm{CM}}$ is equal to $i_{\mathrm{L}}$. This means that the electrolytic capacitor $C_{\mathrm{M}}$ is also discharged rapidly. Thus, $v_{\mathrm{CM}}$ is reduced by $2 i_{\mathrm{L}} R_{\mathrm{S}}$ in a short time. Here, the authors claim that the inner-series resistor can be realized without any power consumption.

\section{Simulation Results}

The validity and high applicability of the proposed largecapacity capacitor simulator with improved source current control are confirmed using PSIM software. Table 1 shows the circuit constants for Fig. 1, which are used in the digital computer simulation.

3.1 Ideal Large-capacity Capacitor Simulator An ideal large-capacity capacitor operation is demonstrated. Fig. 4 shows the simulation waveforms for the circuit in Fig. 1 with no inner-series resistors, where the control gain $K$ in (2)
Table 1. Circuit constants for Fig. 1

\begin{tabular}{l|l|l}
\hline \hline Switching inductor for PWM rectifier & $L_{\mathrm{S}}$ & $2 \mathrm{mH}$ \\
\hline Switching inductor for bidirectional chopper & $L_{\mathrm{Ch}}$ & $20 \mathrm{mH}$ \\
\hline Main electrolytic capacitor & $C_{\mathrm{M}}$ & $1 \mathrm{mF}$ \\
\hline DC capacitor & $C_{\mathrm{DC}}$ & $3.3 \mathrm{mF}$ \\
\hline DC-capacitor voltage & $V_{D C}^{*}$ & $200 \mathrm{~V}$ \\
\hline Load current & $i_{\mathrm{L}}$ & $\pm 5 \mathrm{~A}$ \\
\hline Switching frequency & $f_{\mathrm{SW}}$ & $15 \mathrm{kHz}$ \\
\hline
\end{tabular}

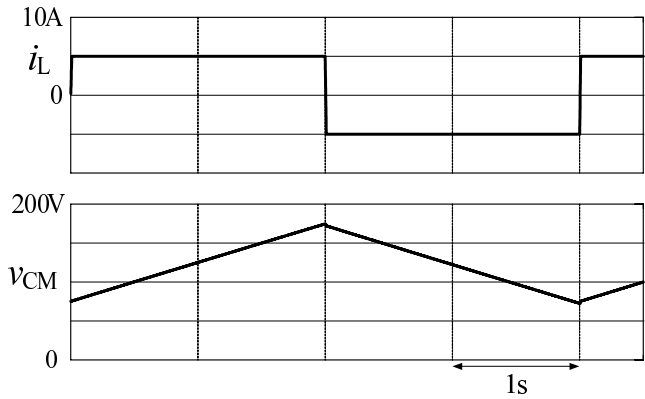

Fig. 4. Simulation waveforms for Fig. 1(a)

is 100. Thus, the proposed simulator acts as a capacitor of $0.1 \mathrm{~F}$. In Fig. $4, i_{\mathrm{L}}$ is the load current waveform and $v_{\mathrm{CM}}$ is the electrolytic capacitor voltage waveform. $v_{\mathrm{CM}}$ increases linearly during the capacitor-charging operation even though $C_{\mathrm{M}}$ is $1 \mathrm{mF}$ because the load current $i_{\mathrm{L}}$ is constant at $5 \mathrm{~A}$. Under the capacitor-discharging operation, $v_{\mathrm{CM}}$ linearly decreases. The capacity of the proposed large-capacity capacitor simulator is now calculated from the simulation results shown in Fig. 4. The capacitor voltage $v_{\mathrm{CM}}$ is increased by $100 \mathrm{~V}$ in $2 \mathrm{~s}$ under the charging operation. The equivalent capacity $C_{\text {Sim }}$ given by (2) is calculated as

$$
\begin{aligned}
C_{\text {Sim }} & =\frac{5 \mathrm{~A} \cdot 2 \mathrm{~s}}{100 \mathrm{~V}} \\
& =0.1 \mathrm{~F} . \cdots
\end{aligned}
$$

According to the equation (5), the proposed simulator acts as a large-capacity capacitor $C_{\text {Sim }}$ of $0.1 \mathrm{~F}$ with a control gain $K$ of 100. Fig. 5 shows the source voltage and current waveforms $v_{\mathrm{S}}$ and $i_{\mathrm{S}}$ respectively. (a) shows $v_{\mathrm{S}}$ and $i_{\mathrm{S}}$ during the capacitor-charging operation. Most of the power from the load current is injected to the utility through the single-phase PWM rectifier. (b) shows $v_{\mathrm{S}}$ and $i_{\mathrm{S}}$ during the capacitordischarging operation. Most of the power supplied to the load is also from the utility through the PWM rectifier. Thus, the proposed simulator acts as a large-capacity capacitor with no power consumption under both charging and discharging operations ${ }^{(4)}$. The phase difference between $v_{\mathrm{S}}$ and $i_{\mathrm{S}}$ is exactly $180^{\circ}$ in (a). In (b), the source current $i_{\mathrm{S}}$ is in-phase to the source voltage $v_{\mathrm{S}}$. The steady-state error is completely avoided by the current feedback control on the d-q coordinates in single-phase circuits.

3.2 SC Simulator We now demonstrate an SC simulator, in which an inner-series resistor should be included ${ }^{(8)}$. In the following simulation results, an inner-series resistor $R_{\mathrm{S}}$ of $2 \Omega$ is considered. The theoretical voltage jump at the change in the operation mode is $20 \mathrm{~V}$, where the control gain $K$ is 1 for $5 \mathrm{~ms}$. Fig. 6 shows the simulation waveforms for the proposed simulator of Fig. 1 . The capacitor voltage $v_{\mathrm{CM}}$ is increased or decreased by $100 \mathrm{~V}$ in $2 \mathrm{~s}$ during the charging or discharging operation, respectively, with a constant 


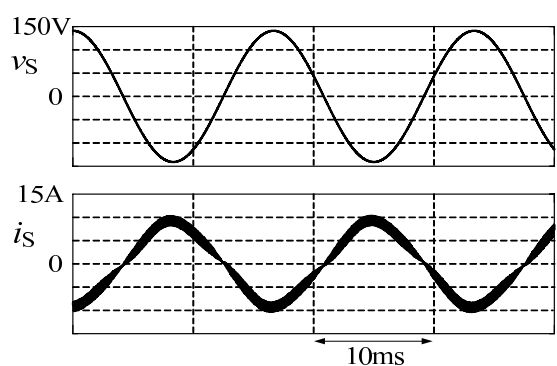

(a) Under capacitor-charging operation
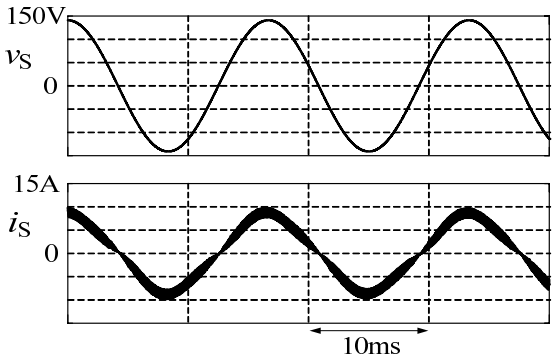

(b) Under capacitor-discharging operation.

Fig. 5. Source voltage $v_{\mathrm{S}}$ and current $i_{\mathrm{S}}$ waveforms

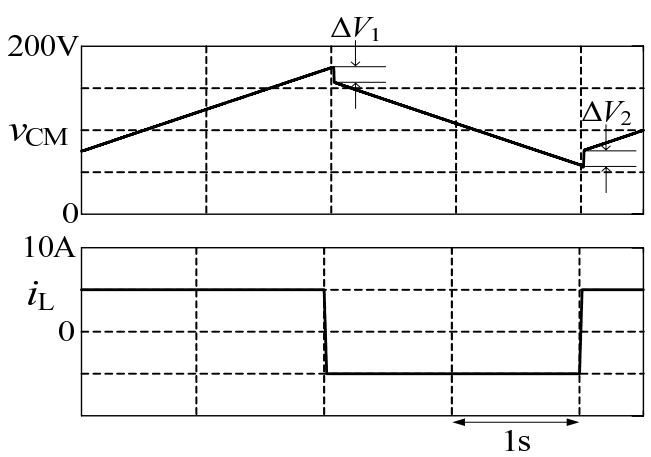

Fig. 6. Simulation waveforms for Fig. 1(a) under the SC operation

load current $i_{\mathrm{L}}$ of $5 \mathrm{~A}$. Thus, the proposed simulator acts as a large-capacity capacitor $C_{\text {Sim }}$ of $0.1 \mathrm{~F}$ with a control gain $K$ of 100 . The voltage jumps $\Delta V_{1}$ and $\Delta V_{2}$ are both $20 \mathrm{~V}$. This means that the proposed large-capacity capacitor simulator acts as an $\mathrm{SC}$, where the inner-series resistor $R_{\mathrm{S}}$ is $2 \Omega$ with $C_{\text {Sim }}=0.1 \mathrm{~F}$. Fig. 7 shows the magnified waveforms in Fig. 6 when the operation mode was changed, where (a) shows the change from discharging to charging and (b) shows the change from charging to discharging. From $t_{0}$ to $t_{1}$, a duration of $10 \mathrm{~ms}$, the load current $i_{\mathrm{L}}$ was gradually decreased to avoid the instability of the PI controller in the bidirectional chopper. At $t_{1}$, the operation mode of the proposed simulator was changed from charging to discharging. The leg consisting of $\mathrm{Q}_{1}$ and $\mathrm{Q}_{2}$ acts as a buck converter. From $t_{1}$ to $t_{2}$, the control gain $K$ is 1.0. The electrolytic capacitor $C_{\mathrm{M}}$ was heavily discharged. Thus, the voltage $v_{\mathrm{CM}}$ jumped by $20 \mathrm{~V}$ while acting as an inner-series resistor of $2 \Omega$. The theoretical time in which $v_{\mathrm{CM}}$ jumped by $20 \mathrm{~V}$ is $4 \mathrm{~ms}$ when $K=1$. In Fig. 7, however, the time in which $v_{\mathrm{CM}}$ jumped by $20 \mathrm{~V}$ is $5 \mathrm{~ms}$. This is due to the response of the PI controller used in the bidirectional dc-dc converter. From $t_{2}$ to $t_{3}$, the phase difference between $v_{\mathrm{S}}$ and $i_{\mathrm{S}}$ is remained. This is because the $T_{\mathrm{S}} / 4$ transport delay block is included in the source current control block on d-q coordinates in single-phase circuits.
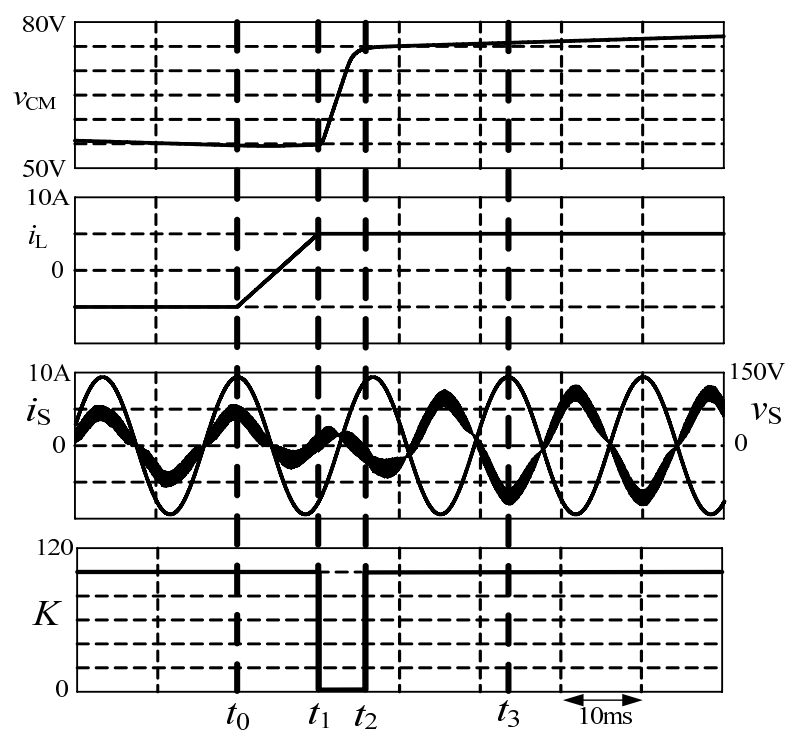

(a) From discharging to charging.
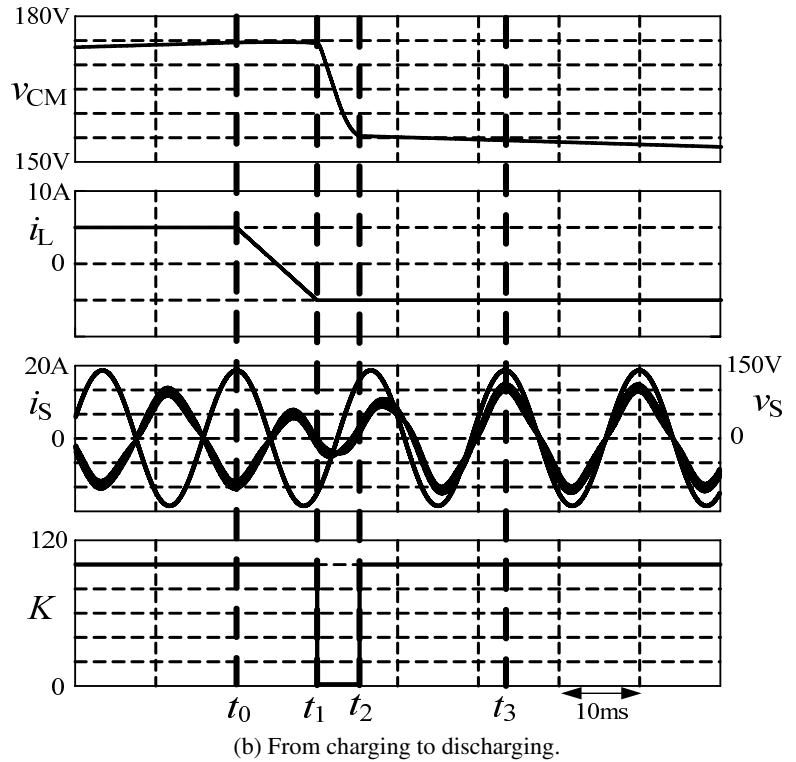

Fig. 7. Magnified waveforms in Fig. 6

Thus, the settling time of the source current $i_{\mathrm{S}}$ is theoretically larger than $T_{S} / 4$. At $t_{3}$, the operation mode is perfectly changed from discharging to charging or from charging to discharging. From these simulation results, we see that the proposed large-capacity capacitor simulator can perform not only as an ideal large-capacity capacitor but also as an SC with no power consumption.

\section{Experimental Results}

A prototype experimental model was constructed and tested to verify the validity and high applicability of the proposed large-capacity capacitor simulator. Fig. 8 shows a block diagram of the constructed experimental model for Fig. 1(a). A dc source (Takasago: HX0300-25) was used for the load-side current source $i_{\mathrm{L}}$ under the capacitor-charging operation. Under the capacitor-discharging operation, an electronic load (Fujitsu: EUL-300 $\alpha \mathrm{XH}$ ) was used for $i_{\mathrm{L}}$. The detected $v_{\mathrm{S}}, i_{\mathrm{S}}, i_{\mathrm{Ch}}$ and $v_{\mathrm{DC}}$ were fed to a DSP (digital signal processor: TMS320C6713, 225 MHz) through 12bit A/D 


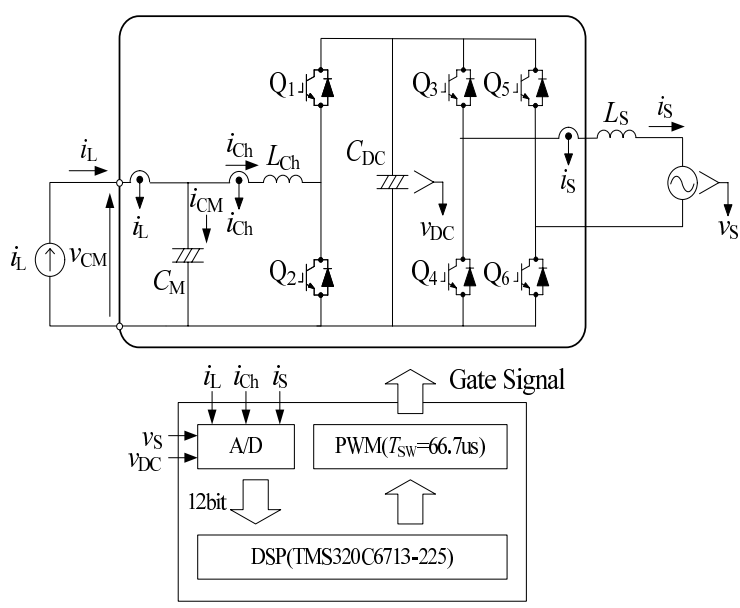

Fig. 8. Block diagram of the constructed experimental model for Fig. 1(a)

converters, where the sampling time $T_{\mathrm{S}}$ was $66.7 \mu \mathrm{s}$. In the DSP, the control schemes shown in Fig. 2 were carried out. The circuit constants shown in Table 1 were also used in the constructed experimental model.

4.1 Ideal Large-capacity Capacitor Simulator An ideal large-capacity capacitor operation was demonstrated experimentally. Fig. 9 shows the experimental results for Fig. 1 with no inner-series resistors, where the control gain $K$ in (2) is 100 . Thus, the proposed simulator acts as a capacitor of $0.1 \mathrm{~F}$. $i_{\mathrm{L}}$ is the load current waveform and $v_{\mathrm{CM}}$ is the electrolytic capacitor voltage waveform. $v_{\mathrm{CM}}$ increases linearly during the capacitor-charging operation even though $C_{\mathrm{M}}$ is $1 \mathrm{mF}$. The capacity of the proposed large-capacity capacitor simulator is calculated from the experimental results shown in Fig. 9. The capacitor voltage $v_{\mathrm{CM}}$ is increased by $10.6 \mathrm{~V}$ in $0.2 \mathrm{~s}$ under the charging operation. The equivalent capacity $C_{\text {Sim }}$ given by (2) is

$$
\begin{aligned}
C_{\text {Sim }} & =\frac{5 \mathrm{~A} \cdot 0.2 \mathrm{~s}}{10.6 \mathrm{~V}} \\
& =0.094 \mathrm{~F} .
\end{aligned}
$$

According to the equation (6), the proposed simulator acts as a large-capacity capacitor $C_{E}$ of $0.1 \mathrm{~F}$ with a control gain $K$ of 100 .

Fig. 10 shows the experimental results for Fig. 1 under the capacitor discharging operation. The capacitor voltage $v_{\mathrm{CM}}$ is decreased by $10.2 \mathrm{~V}$ in $0.2 \mathrm{~s}$ under the discharging operation. The equivalent capacity $C_{\text {Sim }}$ given by (2) is calculated as

$$
\begin{aligned}
C_{\text {Sim }} & =\frac{5 \mathrm{~A} \cdot 0.2 \mathrm{~s}}{10.2 \mathrm{~V}} \\
& =0.098 \mathrm{~F} .
\end{aligned}
$$

From the equations (6) and (7), the constructed experimental model in Fig. 8 acted as an ideal large-capacity capacitor simulator with a capacitance of $0.1 \mathrm{~F}$.

4.2 SC Simulator We now demonstrate the SC simulator with an inner-series resistor. In the following experimental results, a capacity $C_{\text {Sim }}$ of $0.1 \mathrm{~F}$ with an inner-series resistor $R_{S}$ of $2 \Omega$ was considered. In the simulation results shown in Fig. 6, a bidirectional dc source was used for the load-side current $i_{\mathrm{L}}$. There is, however, no bidirectional dc source with a rapid response. Thus, we have demonstrated

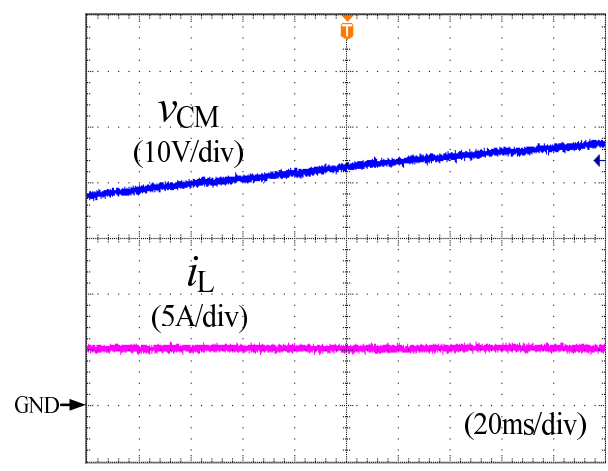

Fig. 9. Experimental waveforms under the charging operation

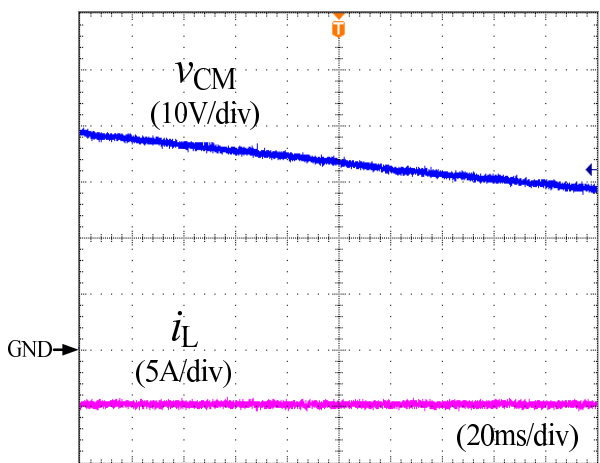

Fig. 10. Experimental waveforms under the discharging operation

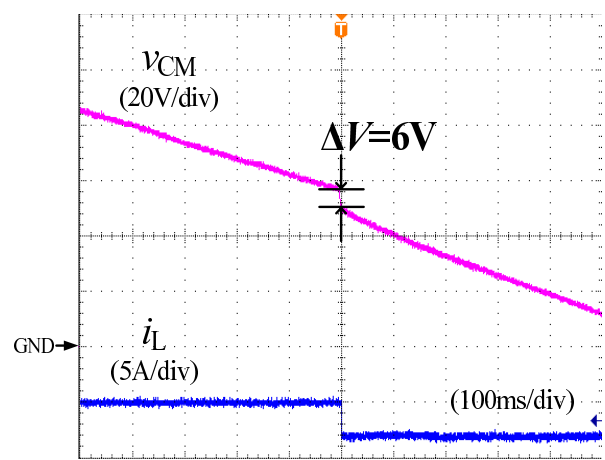

Fig. 11. Experimental waveforms under the SC operation

the inner-series resistor $R_{\mathrm{S}}$ with a step change of $i_{\mathrm{L}}$ under the discharging operation.

Fig. 11 shows experimental waveforms for Fig. 1, where the inner-series resistor $R_{\mathrm{S}}$ is considered. The load current $i_{\mathrm{L}}$ was changed from $-5 \mathrm{~A}$ to $-8 \mathrm{~A}$ under the discharging operation. Thus, the theoretical value of the voltage jump $\Delta V$ is $6 \mathrm{~V}$. In the experimental results shown in Fig. 11, the voltage $v_{\mathrm{CM}}$ of the proposed capacitor simulator jumped by $6 \mathrm{~V}$. This means that the proposed simulator acted as an inner-series resistor $R_{\mathrm{S}}$ of $2 \Omega$. $v_{\mathrm{CM}}$ was decreased by $27 \mathrm{~V}$ in $500 \mathrm{~ms}$ when $i_{\mathrm{L}}$ was $-5 \mathrm{~A}$. The equivalent capacity $C_{\mathrm{Sim}}$ given by (2) is calculated as

$$
\begin{aligned}
C_{\text {Sim }} & =\frac{5 \mathrm{~A} \cdot 500 \mathrm{~ms}}{27 \mathrm{~V}} \\
& =0.093 \mathrm{~F} . \ldots
\end{aligned}
$$

When $i_{\mathrm{L}}$ was $-8 \mathrm{~A}, v_{\mathrm{CM}}$ was decreased by $42 \mathrm{~V}$ in $500 \mathrm{~ms}$. Thus, $C_{\text {Sim }}$ is given as 


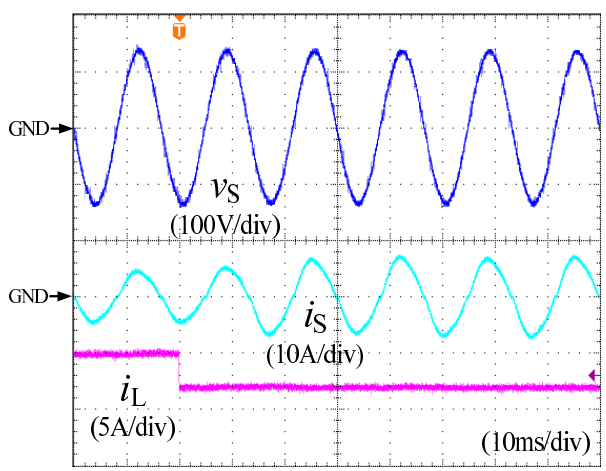

Fig. 12. Source voltage $v_{\mathrm{S}}$ and current $i_{\mathrm{L}}$ waveforms

$$
\begin{aligned}
C_{\text {Sim }} & =\frac{8 \mathrm{~A} \cdot 500 \mathrm{~ms}}{42 \mathrm{~V}} \\
& =0.095 \mathrm{~F} . \cdots
\end{aligned}
$$

Therefore, the proposed large-capacity capacitor simulator acted as an $\mathrm{SC}$ of $0.1 \mathrm{~F}$ with an inner-series resistor $R_{\mathrm{S}}$ of $2 \Omega$.

Fig. 12 shows waveforms for the source voltage $v_{\mathrm{S}}$, source current $i_{\mathrm{S}}$, and load current $i_{\mathrm{L}} . i_{\mathrm{S}}$ is increased by the change in $i_{\mathrm{L}}$. The source current $i_{\mathrm{S}}$ is in-phase to the source voltage $v_{\mathrm{S}}$ by the current control on the d-q coordinates in single-phase circuits. These experimental results agree well with the simulation results in Section 3.

\section{Conclusions}

In this paper, a universal large-capacity capacitor simulator using a single-phase PWM rectifier and a bidirectional dc-dc converter has been proposed. The proposed simulator consists of three-leg IGBTs. One of the three legs acts as a bidirectional dc-dc converter. The others are used as a single-phase PWM rectifier. During the charging operation, one-leg acts as a boost converter. Most of the power stored in the electrolytic capacitor in the proposed simulator is injected to the utility through the PWM rectifier. The same-leg acts as a buck converter during the discharging operation. Most of the power supplied to the load is from the utility through the PWM rectifier. Thus, the proposed simulator acts as a large-capacity capacitor in both the charging and discharging operations. For the operation of an SC simulator, inner-series resistors should be considered. A new control method, which can act as an inner-series resistor, has been also proposed. The basic principle of the proposed capacitor simulator was discussed in detail and then confirmed by digital computer simulation using PSIM software. A prototype experimental model was constructed and tested to verify the validity and high applicability of the proposed large-capacity capacitor simulator. Experimental results demonstrated that the proposed capacitor simulator performs as both an ideal large-capacity capacitor and an SC with an inner-series resistor.

The authors conclude that the proposed large-capacity capacitor, both with and without an inner-series resistor, is useful for prototype voltage sag compensators and so forth in the laboratory.
Future work is comparison of characteristics of an actual $\mathrm{SC}$ and the proposed capacitor simulator. Furthermore, an evaluation of the proposed capacitor simulator in the power electronics circuit is also our future work.

\section{References}

( 1 ) S. Komori, M. Kimura, K. Watanabe, T. Takazoe, T. Naoi, T. Miyao, K. Higashiyama, H. Yamashita, and M. Watanabe: "Compact Fuel Processor by Employing Monolithic Catalyst for $1 \mathrm{~kW}$ Class Residential Polymer Electrolyte Fuel Cells", Journal of the Japan Petroleum Institute, Vol.54, No.1, pp.52-55 (2011) (in Japanese)

( 2 ) H. Shirato, Y. Hamada, T. Suda, M. Sakairi, Y. Oka, H. Hayashi, H. Ikeda, and K. Nagano: "Study on Hydrogen Storage System for Residential Energy System and Independent Power Supply with Hydrogen Absorbing Alloys and Air Heat Exchange Type Container: Part3-Energy Conservation Effect and Installation Analysis of Passive Hydrogen Storage Systems for Fuel Cell CHP Systems", Journal of the Society of Heating, Air-Conditioning and Sanitary Engineers of Japan, Vol.171, pp.1-7 (2011) (in Japanese)

( 3 ) N. Katayama and S. Kogoshi: "Fuel Cell/Electric Double Layer Capacitor Hybrid Power Source Using a Multi-port Bidirectional DC-DC Converter", The Trans. of the Institute of Electrical Engineers of Japan. D, Vol.130, No.11, pp.1279-1280 (2010) (in Japanese)

( 4 ) S. Funabiki, S. Kodama, and M. Yamamoto: "Performance of Electric Double-Layer Capacitor Simulators", IEEJ Trans. on IAS, Vol.127, No.9, pp.1030-1031 (2007) (in Japanese)

( 5 ) S. Richard and C.P. Zhang: "Control of Single Phase Power Converter in DQ Rotating Coordinates", United States Patent, Patent No. US 6621252B2 (2003)

( 6 ) L.N. Arruda, S.M. Silva, and B.J.C. Filho: "PLL Structures for Utility Connected Systems", in Conference Record of the IEEE-IAS Annual Meeting, Chicago, USA, 2001, pp.2655-2660 (2001)

( 7 ) S.M. Silve, B.M. Lopes, B.J.C. Filho, R.P. Campana, and W.C. Bosventura: "Performance Evaluation of PLL Algorithms for Single-Phase GridConnected Systems", in Conference Record of the IEEE-IAS Annual Meeting, Seattle, USA (2004)

( 8 ) M. Sasaki, S. Kinoshita, H. Matsui, K. Tagawa, K. Hayashi, S. Araki, K. Arai, K. Kishi, S. Yamashita, and T. Takahashi: "Investigation of Optimum Test Methods for Electric Double Layer Capacitor (1)", in Coference Record of the IEEJ-IAS Annual Meeting, Vol.1, pp.587-590 (2006) (in Japanese)

Masayuki Okamoto (Member) was born in 1971. He received the

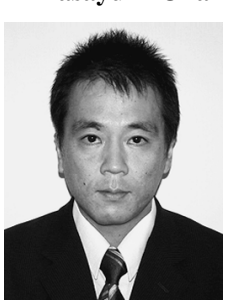
M.S. and Ph.D. degrees in electrical engineering from Yamaguchi University in 1996 and 1999, respectively. From 1999 to 2012, he was an Assistant Professor at Yamaguchi University. Since 2012, he has been an Associate Professor at Ube National College of Technology. His research interests include device modeling of $\mathrm{GaN}$-based switching devices and design of a high frequency power electronic converter with the switching devices. He is a member of the IEEE.

Eiji Hiraki (Member) was born in 1964. He received the M.S. and

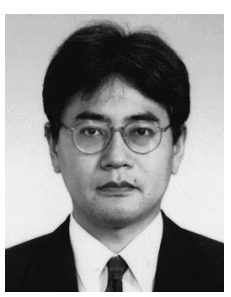
$\mathrm{Ph} . \mathrm{D}$. degrees in electrical engineering from Osaka University in 1990 and 2004, respectively. From 1995 to 2007, he was a Research Associate with the Power Electronics Laboratory at Yamaguchi University, where he is currently an Associate Professor. His research interests include the soft-switching technique for high-frequency switching power conversion systems. He is a member of the IEEE. 
Toshihiko Tanaka (Senior Member) was born in 1959. He received

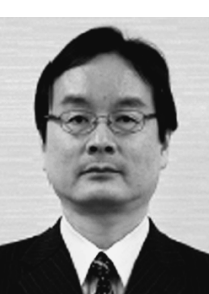
the M.S. degree in electrical engineering from Nagaoka University of Technology in 1984, and the Ph.D. degree from Okayama University in 1995. He joined Toyo Denki Manufacturing Co. in 1984. From 1991 to 1997, he was an Assistant Professor at the Polytechnic University of Japan. From 1997 to 2004, he was an Associate Professor at Shimane University.

Since 2004, he has been a Professor at Yamaguchi University. His research interests include harmonics generated by static power converters and their compensation. He is a member of the IEEE.
Atsushi Tanaka (Non-member) was born in 1986. He received the

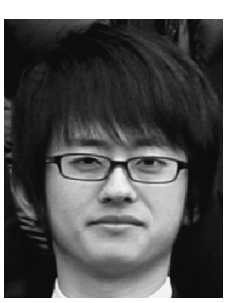
B.S. and M.S. degrees in electrical and electronic engineering from Yamaguchi University in 2009 and 2011, respectively. Since 2011, he has been with the the Chugoku Electric Power Co., Inc. 